\title{
Short communication: Staphylococcus aureus infection modulates expression of drug transporters and inflammatory biomarkers in mouse mammary gland
}

\author{
A. Oskarsson, ${ }^{* 1}$ Y. Yagdiran, ${ }^{*}$ S. Nazemi, $\dagger$ J. Tallkvist, ${ }^{*}$ and C. H. Knight $\dagger$ \\ *Department of Biomedical Sciences and Veterinary Public Health, Swedish University of Agricultural Sciences, SE-750 07 Uppsala, Sweden \\ †Department of Veterinary Clinical and Animal Sciences, University of Copenhagen, SUND IKVH, 1870 Frb C, Denmark
}

\begin{abstract}
Mastitis is the most common disease in dairy herds worldwide and is often caused by Staphylococcus aureus. Little is known about the effect of mastitis on transporters in the mammary gland and the effect on transporter-mediated secretion of drugs into milk. We studied gene expressions of ATP-binding cassette and solute carrier transporters in $S$. aureus-infected mammary glands of mice. On d 7 of lactation, NMRI mice were inoculated with 1,000 cfu of $S$. aureus in 2 mammary glands and with a saline vehicle in 2 control glands. Gene expression of the transporters, Bcrp, Mdr1, Mrp1, Oatp1a5, Octn1, and Oct1, and of Csn2, the gene encoding $\beta$-casein, were determined in mammary glands at $72 \mathrm{~h}$ after treatment. As biomarkers of the inflammatory response gene, expressions of the cytokines Il6, Tnfo, and the chemokine Cxcl2 were measured. Despite a high individual variation between the 6 animals, some characteristic patterns were evident. The 3 inflammatory biomarkers were upregulated in all animals; Csn2 was downregulated compared with controls in all animals, although not statistically significantly. Both Mrp1 and Oatp1a5 were statistically significantly upregulated and Bcrp was downregulated. Gene expression of Bcrp followed the expression of Csn2 in each of the animals, indicating a possible coregulation. The findings demonstrate that $S$. aureus infection has an effect on expression of drug transporters in the mammary gland, which may affect secretion of drugs into milk and efficacy of drug therapy.
\end{abstract}

Key words: mastitis, drug transporters, mammary gland, Staphylococcus aureus

\section{Short Communication}

Staphylococcus aureus is recognized to be a major contagious mammary pathogen, causing clinical as well

Received June 22, 2016.

Accepted November 12, 2016.

${ }^{1}$ Corresponding author: agneta.oskarsson@slu.se as subclinical mastitis in cattle (Bradley, 2002; Roy and Keefe, 2012; Royster and Wagner, 2015); it frequently gives rise to persistent and chronic infections (Degen et al., 2015) and, hence, significant economic loss for dairy producers (Bradley, 2002). Drug transporters belonging to the ATP-binding cassette (ABC) and solute carrier (SLC) superfamilies are membrane proteins mediating active or facilitated cellular influx and efflux transport of endogenous compounds, numerous drugs, and other chemicals (Sai and Tsuji, 2004; Klaassen and Aleksunes, 2010; Schuetz et al., 2014; Chen et al., 2016). Individual members of the superfamilies, such as breast cancer resistance protein (BCRP/ABCG2), multidrug resistance protein 1 (MDR1/ABCB1), multidrug resistance-associated protein 1 (MRP1/ABCC1), solute carrier organic anion transporter family member 1 A2 (OATP1A2/SLCO1A2; the bovine ortholog to the murine Oatp1a5), organic cation transporter novel protein type 1 (OCTN1/SLC22A4), and organic cation transporter 1 (OCT1/SLC22A1), are expressed differentially during the pregnancy-lactation cycle in mammary epithelial cells of cattle (Farke et al., 2008; Mani et al., 2009), mice and rats (Gilchrist and Alcorn, 2010; Lamhonwah et al., 2011; Ito et al., 2014; Yagdiran et al., 2016), and humans (Alcorn et al., 2002; Jonker et al., 2005). Emerging evidence has demonstrated that infection and inflammation in various tissues affect the expression and function of transporters with impact on drug distribution and efficacy of therapy (Petrovic et al., 2007; Martinez et al., 2008; Morgan et al., 2008; Cressman et al., 2012, 2014; Gandhi et al., 2012). Reported data are mainly from liver, intestine, kidney, brain, and placenta, and little is known about the effect of inflammation in the mammary gland on the expression of transporters. This is surprising due to the high incidence of mastitis in dairy herds; likewise, the potential effect of inflammation on drug transporters could have an effect on milk quality, by modulating excretion of nutrients and toxic compounds into milk, and on the therapeutic efficacy of drugs, which are ligands of the transporters. In the present study, we tested the hypothesis that $S$. aureus-induced mammary inflam- 
mation might affect gene expression of $\mathrm{ABC}$ and SLC transporters in the mouse mammary gland.

We used a mouse model of $S$. aureus-induced mammary inflammation to study the effect of gene expression of ABC and SLC transporters, known to vary with lactation stage. As an indicator of milk protein synthesis, expression of Csn2 (the gene encoding $\beta$-casein) was measured, and, as biomarkers of inflammatory response, the proinflammatory cytokines Il6 and Tnfa and the chemokine $C x c l 2$ were determined. The procedure for inducing mouse mammary inflammation by a $S$. aureus challenge has been described by Nazemi et al. (2014). Our experiment was performed according to the guidelines of the European Convention for protection of Vertebrate Animals and Animal Experimentation Act under Danish national legislation (Miljø- og Fødevareministeriet, 2013) and conducted at Technical University of Denmark (Lyngby, Denmark; license number: 2012-15-2934-00587). Briefly, 6 lactating NMRI mice were treated under anesthesia with $S$. aureus on d $7 \pm 2$ of lactation (10 pups/litter). In each mouse, the fourth and fifth inguinal glands on one side were infused with $100 \mu \mathrm{L}$ of a $S$. aureus AO35 $(10,000 \mathrm{cfu} / \mathrm{mL})$ suspension, whereas the 2 contralateral inguinal glands were infused with $100 \mu \mathrm{L}$ of a physiological saline vehicle. Following inoculation, mothers were kept separated from pups for $4 \mathrm{~h}$ to obtain better colonization of the bacteria. After $72 \mathrm{~h}$, the mice were anaesthetized and euthanized by cervical dislocation and the treated mammary glands were collected, frozen in liquid nitrogen, and stored at $80^{\circ} \mathrm{C}$.

To isolate total RNA, frozen mammary glands were cut into smaller pieces of 20 to $25 \mathrm{mg}$ on dry ice. The 2 treated mammary glands from each mouse were pooled, as were the 2 controls, and the tissues were homogenized with Trizol (Life Technologies Europe, Naerum, Denmark) and frozen stainless steel beads $(5 \mathrm{~mm}$, cat. no. 69989; Qiagen, Hilden, Germany) with TissueLyser II from Qiagen (cat. no. 85300). After centrifugation at $10,000 \times g$ for $10 \mathrm{~min}$ at $4^{\circ} \mathrm{C}$, the supernatants were transferred into MaXtract High Density $1.5-\mathrm{mL}$ tubes (cat. no. 129046; Qiagen). Final isolation of RNA was performed by using SV Total RNA isolation system kit from Promega (Nacka, Sweden) according to the guidelines. Quantification of the RNA was performed with the RNA specific Quant-iT RiboGreen-kit according to the manufacturer (Thermo Fisher Scientific, Stockholm, Sweden). Sequences of the primers of transporters and Csn2 are described by Yagdiran et al. (2016). Gene-specific intron-spanning primers to murine [ $\mathrm{Cxcl} 2$ (forward) 5'-TCCAGAGCTTGAGTGTGACG-3 and (reverse) 5'-CTTTGGTTCTTCCGTTGAGG-3; Il6 (forward) 5'-AGTTGCCTTCTTGGGACTGA-3 and (reverse) 5'-TCCACGATTTCCCAGAGAAC-3; and Tnfo (forward) 5'-AGCCCCCAGTCTGTATCCTT-3 and (reverse) 5'-CTCCCTTTGCAGAACTCAGG-3] were designed by the use of the Genome Browser (University of California, Santa Cruz) and Primer3 software (SimGene.com). The primers were synthetized by Cybergene (Huddinge, Sweden). Quantitative gene expression was examined by real-time quantitative reverse-transcription PCR (RT-qPCR) using a RotorGene 3000 (Corbett Research, Mortlake, Australia) by applying the One-tube QuantiTectSYBR Green RT-PCR Kit (Qiagen Nordic, Sollentuna, Sweden) according to the manufacturer's recommendations. Prior to RT-qPCR analysis, the specificity of all primer pairs were tested on murine mammary RNA and shown to generate specific RT-qPCR products with anticipated amplicon sizes and single melting curve peaks. Final primer concentration for all target genes was $0.4 \mu M$, and 75 or $150 \mathrm{ng}$ of total RNA was used as template in 12.5- $\mu \mathrm{L}$ RT-qPCR reactions. Nontemplate controls served as blanks and melting curve analysis was performed for each sample to check the specificity of the obtained PCR products. Expressions of target genes were normalized to the geometric average expression of 3 appropriate reference genes (Bustin et al., 2009). As reference genes in mouse mammary gland (as recommended by Han et al., 2010), we used hypoxanthineguanine phosphoribosyltransferase (Hprt), ribosomal protein L13A (Rpl13a), and glyceraldehyde 3-phosphate dehydrogenase (Gapdh). Relative quantification of mRNA expressions was performed by comparing the quantification cycle (Cq) between the tissues and treatment groups of cells according to the $2^{-(\Delta \Delta \mathrm{Cq})}$ method (Livak and Schmittgen, 2001); Cq 35 was used as cut-off for limit of detection of gene expression. Fold differences were calculated by setting vehicle controls to 1 .

Statistical analyses were performed using Minitab 16 software (Minitab Inc., State College, PA). The results were analyzed by Kruskal-Wallis to detect any significant differences among the treatment groups, followed by Mann-Whitney to examine statistically significant differences between 2 groups. The level of significance was set at $P<0.05$.

Figure 1 shows individual mRNA expressions of the proinflammatory biomarkers, Cxcl2, Il6, and Tnfo, of Csn2, as an indicator of milk protein synthesis, and of the transporters Bcrp, Mdr1, Mrp1, Oatp1a5, Octn1, and Oct1 for each of the 6 mice. The results are expressed as the ratio between treated and control glands. We found common patterns in response, even if the difference in response rate was wide between the animals. Each of the animals responded to the infection 
a

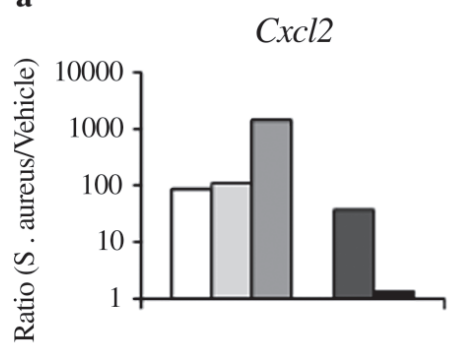

d

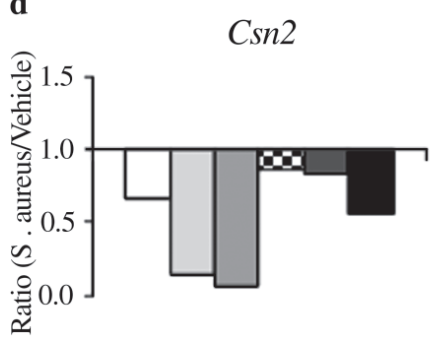

g

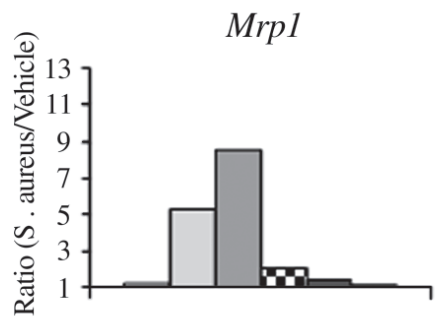

j

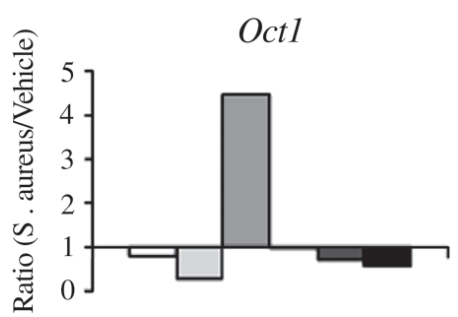

b

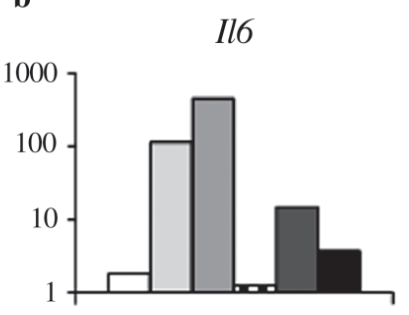

e

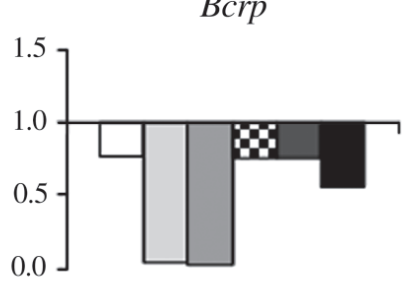

h

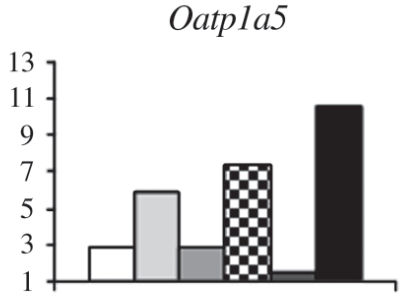

c

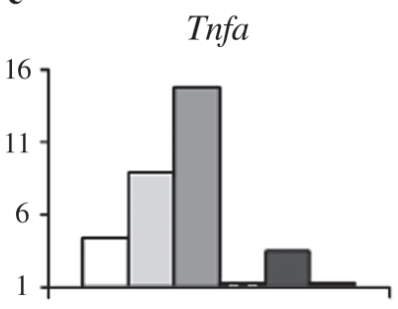

f

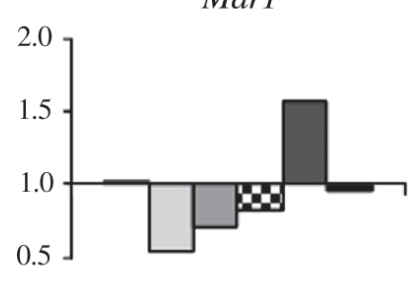

i

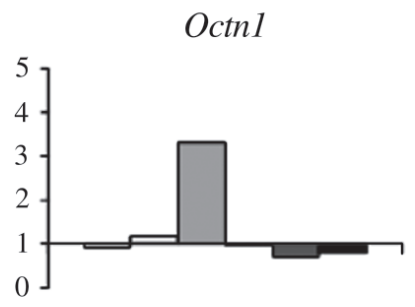

Figure 1. Ratios between gene expressions in treated mammary glands and in vehicle-treated control glands of inflammatory biomarkers (Cxcl2, Il6, and Tnfo), Csn2, and transporters (Bcrp, Mdr1, Mrp1, Oatp1a5, Octn1, and Oct1) $72 \mathrm{~h}$ after treatment with 1,000 cfu of Staphylococcus aureus or control vehicle in mammary glands of mice. Normalized gene expressions are presented as ratios in the 6 individual animals. Scales for Cxcl2 and Il6 are logarithmic.

with a similar expression profile of the inflammatory biomarkers. One of the mice, number 4 , had a very low response, and numbers 2 and 3 had the highest response for all 3 biomarkers. Gene expressions of Csn2 and Bcrp were downregulated in all animals and had almost the same profile, indicating an association and a possible co-regulation. Treatment of animals with $S$. aureus resulted in an upregulation in all animals of Oatp1a5 and Mrp1. Gene expressions of Mdr1 and Oct1 were downregulated in 4 animals and upregulated in 1 , and $\operatorname{Octn} 1$ was only induced in 1 of the treated animals (Figure 1). No statistically significant differences in gene expressions of the reference genes in mammary glands of control and S. aureus-induced animals were detected.

The overall effects of $S$. aureus treatment compared with vehicle controls on gene expression of transporters and the inflammatory biomarkers in mammary gland 


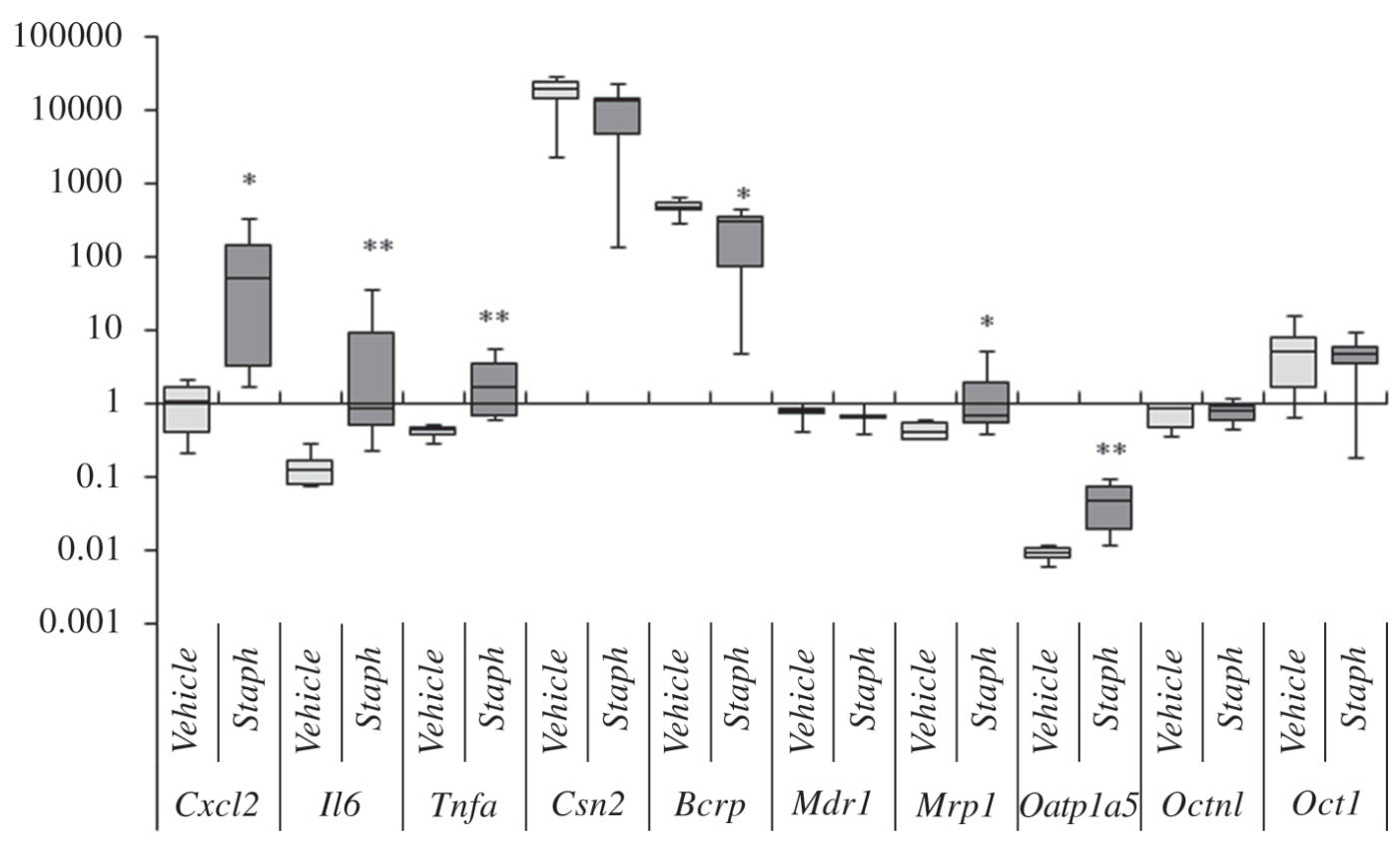

Figure 2. Boxplots with gene expressions of inflammatory biomarkers (Cxcl2, Il6, and Tnf $\alpha$ ), Csn2, and transporters (Bcrp, Mdr1, Mrp1, Oatp1a5, Octn1, and Oct1) $72 \mathrm{~h}$ after treatment of mammary glands of mice with 1,000 cfu of Staphylococcus aureus (Staph) or vehicle controls (Vehicle). Normalized gene expressions are presented as boxplots, in which dark horizontal lines represent the median, with the box representing the 25 th and 75 th percentiles and the whiskers the 5 th and 95th percentiles $(\mathrm{n}=6)$. Statistically significant differences as compared with vehicle controls: $* P<0.05 ; * * P<0.01$.

are illustrated by boxplots in Figure 2, including results from the statistical analysis. Despite the relatively large interindividual variations, the upregulation of the proinflammatory biomarkers was statistically significant, as well as the downregulation of Bcrp and upregulation of Mrp1 and Oatp1a5.

Breast cancer resistance protein is an efflux transporter located at the apical membrane and known to be strongly induced in the mammary gland epithelium during pregnancy and lactation, which may lead to concentration of BCRP ligands, such as drugs and carcinogenic food contaminants in milk (Jonker et al., 2005; van Herwaarden and Schinkel, 2006). Breast cancer resistance protein has a wide substrate specificity, and veterinary drugs transported by BCRP include the antimicrobials ciprofloxacin, enrofloxacin, norfloxacin, danofloxacin, nitrofurantoin (Alvarez et al., 2006; Merino et al., 2006; Pulido et al., 2006; Pérez et al., 2009; Real et al., 2011; Mealey, 2012), and sulfoxide metabolite of the anthelmintic drug monepantel (Mahnke et al., 2016).

Few investigations have reported effects of mastitis on elimination of veterinary drugs in milk, but none have investigated effects on drug transporters. Nonsteroidal anti-inflammatory drugs flunixin (Kissell et al., 2015) and carprofen (Lohuis et al., 1991) were reported at significantly higher concentrations in milk from mastitic cows than from control cows. These drugs are not known to be ligands of efflux transporters, and the increased milk excretion was suggested to be due to increased mammary gland vascular permeability and alteration of the blood-milk barrier. Substances can move into milk either through the transcellular route (uptake across the basolateral membrane, followed by secretion across the apical membrane) or, alternatively, through the paracellular route (movement through leaky tight junctions). Paracellular flux is greatest in very early lactation (and is responsible, in part, for accumulation of immunoglobulins in colostrum), but is also increased during mastitis as part of the local immune defense (Stelwagen and Singh, 2014). However, in contrast to the increased nonsteroidal anti-inflammatory drugs transfer, the BCRP substrates norfloxacin (Gips and Soback, 1999) and ciprofloxacin, the active metabolite of enrofloxacin (Rantala et al., 2002), were found to be excreted into milk in lower concentrations in cows with mastitis compared with healthy animals. This clearly suggests that transcellular mechanisms and membrane transporter proteins are involved. The lower concentrations of BCRP ligands in milk in cows with mastitis may be due to decreased expression of BCRP in the mammary epithelial cells of the animals with inflammation compared with in healthy cows. To our knowledge, this is the first study to show effects on drug transporters in an in vivo mastitis model. Our findings demonstrate that $S$. aureus infection has an effect on expression of 
drug transporters in the mammary gland, which may affect secretion of drugs into milk and efficacy of drug therapy.

\section{ACKNOWLEDGMENTS}

This research project was funded by a grant from the research program TvärLivs, which is co-sponsored by the Swedish Research Council for Environment, Agricultural Sciences and Spatial Planning (Formas; Stockholm, Sweden), Sweden's Innovation Agency (Vinnova; Stockholm, Sweden), Swedish Farmer's Foundation for Agricultural Research (Stockholm, Sweden), the Swedish Food Federation (Stockholm, Sweden), and the Swedish Food Retailer's Federation (Stockholm, Sweden).

\section{REFERENCES}

Alcorn, J., X. Lu, J. A. Moscow, and P. J. McNamara. 2002. Transporter gene expression in lactating and nonlactating human mammary epithelial cells using real-time reverse transcriptionpolymerase chain reaction. J. Pharmacol. Exp. Ther. 303:487-496. https://doi.org/10.1124/jpet.102.038315.

Alvarez, A. I., G. Merino, A. J. Molina, M. M. Pulido, Q. A. McKellar, and J. G. Prieto. 2006. Role of ABC transporters in veterinary drug research and parasite resistance. Curr. Drug Deliv. 3:199-206.

Bradley, A. 2002. Bovine mastitis: An evolving disease. Vet. J. 164:116-128.

Bustin, S. A., V. Benes, J. A. Garson, J. Hellemans, J. Huggett, M. Kubista, R. Mueller, T. Nolan, M. W. Pfaffl, G. L. Shipley, J. Vandesompele, and C. T. Wittwer. 2009. The MIQE guidelines: Minimum information for publication of quantitative realtime PCR experiments. Clin. Chem. 55:611-622. https://doi. org/10.1373/clinchem.2008.112797.

Chen, Z., T. Shi, L. Zhang, P. Zhu, M. Deng, C. Huang, T. Hu, L. Jiang, and J. Li. 2016. Mammalian drug efflux transporters of the ATP binding cassette (ABC) family in multidrug resistance: A review of the past decade. Cancer Lett. 370:153-164. https://doi. org/10.1016/j.canlet.2015.10.010.

Cressman, A. M., C. R. McDonald, K. Silver, K. C. Kain, and M. Piquette-Miller. 2014. Malaria infection alters the expression of hepatobiliary and placental drug transporters in pregnant mice. Drug Metab. Dispos. 42:603-610. https://doi.org/10.1124/ dmd.113.053983.

Cressman, A. M., V. Petrovic, and M. Piquette-Miller. 2012. Inflammation-mediated changes in drug transporter expression/activity: Implications for therapeutic drug response. Expert Rev. Clin. Pharmacol. 5:69-89. https://doi.org/10.1586/ecp.11.66.

Degen, S., J. H. Paduch, M. Hoedemaker, and V. Kromker. 2015. Factors affecting the probability of bacteriological cure of bovine mastitis. Tierarztl. Prax. Ausg. G Grosstiere Nutztiere 43:222-227. https://doi.org/10.15653/TPG-141082.

Farke, C., H. H. Meyer, R. M. Bruckmaier, and C. Albrecht. 2008. Differential expression of $\mathrm{ABC}$ transporters and their regulatory genes during lactation and dry period in bovine mammary tissue. J. Dairy Res. 75:406-414. https://doi.org/10.1017/ S002202990800335X.

Gandhi, A., B. Moorthy, and R. Ghose. 2012. Drug disposition in pathophysiological conditions. Curr. Drug Metab. 13:1327-1344.

Gilchrist, S. E., and J. Alcorn. 2010. Lactation stage-dependent expression of transporters in rat whole mammary gland and primary mammary epithelial organoids. Fundam. Clin. Pharmacol. 24:205214. https://doi.org/10.1111/j.1472-8206.2009.00760.x.
Gips, M., and S. Soback. 1999. Norfloxacin pharmacokinetics in lactating cows with sub-clinical and clinical mastitis. J. Vet. Pharmacol. Ther. 22:202-208. https://doi.org/10.1046/j.13652885.1999.00210.x.

Han, L. Q., G. Y. Yang, H. S. Zhu, L. F. Wang, Y. J. Guo, W. F. Lu, H. J. Li, and Y. L. Wang. 2010. Selection and use of reference genes in mouse mammary glands. Genet. Mol. Res. 9:449-456. https://doi.org/10.4238/vol9-1gmr724.

Ito, N., K. Ito, Y. Ikebuchi, T. Kito, H. Miyata, Y. Toyoda, T. Takada, A. Hisaka, M. Honma, A. Oka, H. Kusuhara, and H. Suzuki. 2014 Organic cation transporter/solute carrier family 22a is involved in drug transfer into milk in mice. J. Pharm. Sci. 103:3342-3348. https://doi.org/10.1002/jps.24138.

Jonker, J. W., G. Merino, S. Musters, A. E. van Herwaarden, E. Bolscher, E. Wagenaar, E. Mesman, T. C. Dale, and A. H. Schinkel. 2005. The breast cancer resistance protein BCRP (ABCG2) concentrates drugs and carcinogenic xenotoxins into milk. Nat. Med. 11:127-129. https://doi.org/10.1038/nm1186.

Kissell, L. W., T. L. Leavens, R. E. Baynes, J. E. Riviere, and G. W. Smith. 2015. Comparison of pharmacokinetics and milk elimination of flunixin in healthy cows and cows with mastitis. J. Am. Vet. Med. Assoc. 246:118-125.

Klaassen, C. D., and L. M. Aleksunes. 2010. Xenobiotic, bile acid, and cholesterol transporters: Function and regulation. Pharmacol. Rev. 62:1-96. https://doi.org/10.1124/pr.109.002014.

Lamhonwah, A. M., L. Mai, C. Chung, D. Lamhonwah, C. Ackerley, and I. Tein. 2011. Upregulation of mammary gland OCTNs maintains carnitine homeostasis in suckling infants. Biochem. Biophys. Res. Commun. 404:1010-1015. https://doi.org/10.1016/j. bbrc.2010.12.100.

Livak, K. J., and T. D. Schmittgen. 2001. Analysis of relative gene expression data using real-time quantitative PCR and the $2(\mathrm{~T})$ (-Delta Delta C) method. Methods 25:402-408. https://doi. org/10.1006/meth.2001.1262.

Lohuis, J. A. C. M., T. Vanwerven, A. Brand, A. S. J. P. A. M. Vanmiert, E. Rohde, B. Ludwig, P. Heizmann, and W. F. Rehm. 1991 Pharmacodynamics and pharmacokinetics of carprofen, a nonsteroidal antiinflammatory drug, in healthy cows and cows with Escherichia coli endotoxin-induced mastitis. J. Vet. Pharmacol. Ther. 14:219-229. https://doi.org/10.1111/j.1365-2885.1991.tb00830.x.

Mahnke, H., M. Ballent, S. Baumann, F. Imperiale, M. von Bergen, C. Lanusse, A. L. Lifschitz, W. Honscha, and S. Halwachs. 2016. The ABCG2 efflux transporter in the mammary gland mediates veterinary drug secretion across the blood-milk barrier into milk of dairy cows. Drug Metab. Dispos. 44:700-708. https://doi.org/10.1124/ dmd.115.068940.

Mani, O., M. T. Sorensen, K. Sejrsen, R. M. Bruckmaier, and C. Albrecht. 2009. Differential expression and localization of lipid transporters in the bovine mammary gland during the pregnancy-lactation cycle. J. Dairy Sci. 92:3744-3756. https://doi.org/10.3168/ jds.2009-2063.

Martinez, M., S. Modric, M. Sharkey, L. Troutman, L. Walker, and K. Mealey. 2008. The pharmacogenomics of P-glycoprotein and its role in veterinary medicine. J. Vet. Pharmacol. Ther. 31:285-300. https://doi.org/10.1111/j.1365-2885.2008.00964.x.

Mealey, K. L. 2012. ABCG2 transporter: Therapeutic and physiologic implications in veterinary species. J. Vet. Pharmacol. Ther. 35:105-112. https://doi.org/10.1111/j.1365-2885.2011.01313.x.

Merino, G., A. I. Alvarez, M. M. Pulido, A. J. Molina, A. H. Schinkel, and J. G. Prieto. 2006. Breast cancer resistance protein (BCRP/ABCG2) transports fluoroquinolone antibiotics and affects their oral availability, pharmacokinetics, and milk secretion. Drug Metab. Dispos. 34:690-695. https://doi.org/10.1124/ dmd.105.008219.

Miljø- og Fødevareministeriet. 2013. Bekendtgørelse af lov om dyrefors $\varnothing$ g, lovbekendtgørelse nr 253. Copenhagen, Miljø- og Fødevareministeriet. Accessed Dec. 20, 2016. https://www.retsinformation. $\mathrm{dk} /$ Forms/R0710.aspx?id=145380.

Morgan, E. T., K. B. Goralski, M. Piquette-Miller, K. W. Renton, G. R. Robertson, M. R. Chaluvadi, K. A. Charles, S. J. Clarke, M. Kacevska, C. Liddle, T. A. Richardson, R. Sharma, and C. J. 
Sinal. 2008. Regulation of drug-metabolizing enzymes and transporters in infection, inflammation, and cancer. Drug Metab. Dispos. 36:205-216. https://doi.org/10.1124/dmd.107.018747.

Nazemi, S., B. Aalbaek, M. Kjelgaard-Hansen, S. Safayi, D. A. Klaerke, and C. H. Knight. 2014. Expression of acute phase proteins and inflammatory cytokines in mouse mammary gland following Staphylococcus aureus challenge and in response to milk accumulation. J. Dairy Res. 81:445-454. https://doi.org/10.1017/ S0022029914000454.

Pérez, M., R. Real, G. Mendoza, G. Merino, J. G. Prieto, and A. I. Alvarez. 2009. Milk secretion of nitrofurantoin, as a specific BCRP/ ABCG2 substrate, in assaf sheep: Modulation by isoflavones. J. Vet. Pharmacol. Ther. 32:498-502. https://doi.org/10.1111/ j.1365-2885.2008.01050.x.

Petrovic, V., S. Teng, and M. Piquette-Miller. 2007. Regulation of drug transporters during infection and inflammation. Mol. Interv. 7:99-111. https://doi.org/10.1124/mi.7.2.10.

Pulido, M. M., A. J. Molina, G. Merino, G. Mendoza, J. G. Prieto, and A. I. Alvarez. 2006. Interaction of enrofloxacin with breast cancer resistance protein (BCRP/ABCG2): Influence of flavonoids and role in milk secretion in sheep. J. Vet. Pharmacol. Ther. 29:279 287. https://doi.org/10.1111/j.1365-2885.2006.00744.x.

Rantala, M., L. Kaartinen, E. Valimaki, M. Stryrman, M. Hiekkaranta, A. Niemi, L. Saari, and S. Pyorala. 2002. Efficacy and pharmacokinetics of enrofloxacin and flunixin meglumine for treatment of cows with experimentally induced Escherichia coli mastitis. J. Vet. Pharmacol. Ther. 25:251-258. https://doi.org/10.1046/j.13652885.2002.00411.x.

Real, R., E. Egido, M. Perez, L. Gonzalez-Lobato, B. Barrera, J. G. Prieto, A. I. Alvarez, and G. Merino. 2011. Involvement of breast cancer resistance protein (BCRP/ABCG2) in the secretion of danofloxacin into milk: Interaction with ivermectin. J. Vet. Pharmacol. Ther. 34:313-321. https://doi.org/10.1111/j.13652885.2010.01241.x.

Roy, J. P., and G. Keefe. 2012. Systematic review: What is the best antibiotic treatment for Staphylococcus aureus intramammary infection of lactating cows in North America? Vet. Clin. North Am. Food. Anim. Pract. 28:39-50. https://doi.org/10.1016/j. cvfa.2011.12.004.

Royster, E., and S. Wagner. 2015. Treatment of mastitis in cattle. Vet. Clin. North Am. Food Anim. Pract. 31:17-46. https://doi. org/10.1016/j.cvfa.2014.11.010.

Sai, Y., and A. Tsuji. 2004. Transporter-mediated drug delivery: Recent progress and experimental approaches. Drug Discov. Today 9:712-720. https://doi.org/10.1016/S1359-6446(04)03198-8.

Schuetz, J. D., P. W. Swaan, and D. J. Tweedie. 2014. The role of transporters in toxicity and disease. Drug Metab. Dispos. 42:541545. https://doi.org/10.1124/dmd.114.057539.

Stelwagen, K., and K. Singh. 2014. The role of tight junctions in mammary gland function. J. Mammary Gland Biol. Neoplasia 19:131138. https://doi.org/10.1007/s10911-013-9309-1.

van Herwaarden, A. E., and A. H. Schinkel. 2006. The function of breast cancer resistance protein in epithelial barriers, stem cells and milk secretion of drugs and xenotoxins. Trends Pharmacol. Sci. 27:10-16. https://doi.org/10.1016/j.tips.2005.11.007.

Yagdiran, Y., A. Oskarsson, C. H. Knight, and J. Tallkvist. 2016 $\mathrm{ABC}$ - and SLC-transporters in murine and bovine mammary epithelium-Effects of Prochloraz. PLoS One 11:e0151904 https:// doi.org/10.1371/journal.pone.0151904. 